\title{
REVISTAMARACANAN
}

Dossiê

\section{O legado científico na sustentação do Império português: a Real Academia Militar do Rio de Janeiro}

\author{
The scientific heritage military world in the uphold of the Portuguese \\ monarchy: the Royal Military Academy of Rio de Janeiro
}

\author{
Juliana Gesuelli Meirelles \\ PUC-CAMPINAS \\ jugmeirelles@gmail.com
}

\begin{abstract}
Resumo: A crise da monarquia absolutista na Europa, ocorrida entre o final do século XVIII e o raiar do século XIX, teve impacto político profundo na condução do Império português, sendo a transferência da corte portuguesa para o Brasil a mudança de maior destaque. Na América, a monarquia bragantina criou inúmeras instituições políticas e culturais no Rio de Janeiro. Assim, o objetivo deste artigo é analisar o universo científico português voltado às atividades militares para perceber o sentido político da criação da Real Academia Militar do Rio de Janeiro (1810) dentro de um projeto de império luso-brasileiro. Inicialmente são apresentadas as linhas gerais dos setores letrados que absorveram as Luzes em Portugal, sua filosofia e os comportamentos culturais voltados para o universo militar entre os governos de D. José e D. Joao VI e, em seguida, analisa-se pelo mesmo prisma o impacto da chegada da corte ao Rio de Janeiro, com destaque para a Real Academia Militar e as características políticas, culturais e científicas desse novo locus de saber.
\end{abstract}

Palavras-chave: Monarquia portuguesa; Política científica; Real Academia Militar do Rio de Janeiro.

Abstract: The crisis of the absolute monarchy in Europe that was on course between the end of the eighteenth century and the dawn of the nineteenth century had a deep political impact on the administration of the Portuguese Colonial Empire, the journey of the Portuguese court to Brazil being the most outstanding change. In the Americas, the Braganza Dynasty founded a variety of political and cultural institutions in the city of Rio de Janeiro. In order to understanding in what measure the foundation of the Royal Military Academy of Rio de Janeiro (1810) has contributed to hold the existence of the Luso-Brazilian Empire this article has the aim of analyzing the Portuguese scientific policy related to the military issues. Firstly, an outline of the literati illustrated regarding the military world under the reigns of Dom José and Dom João VI is presented and, afterwards, the consequences of the Braganza House's arrival in Rio de Janeiro will be analyzed according to the same prism putting focus on the Royal Military Academy and on its political, cultural and scientific characteristics.

Keywords: The Portuguese monarchy; Scientific policy; The Royal Military Academy of Rio de Janeiro. 


\section{As instituições militares no Império português (1750-1821) ${ }^{1}$}

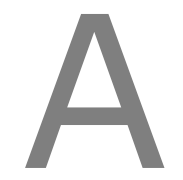

o longo de todo o século XVIII, as academias desempenharam papel central no contexto da ilustração europeia. Sendo um dos principais espaços da sociabilidade letrada, era nas academias que os homens de letras debatiam os temas considerados caros ao progresso da nação pelas luzes da razão. Especificamente no universo luso-brasileiro da primeira metade do século XVIII, os dois grandes destaques vigentes na colônia foram a Academia dos Esquecidos (1724) e a Academia dos Renascidos (1759), ambas situadas em Salvador, à época, capital da América portuguesa. Como bem define a historiadora Iris Kantor, o academicismo desse período foi um importante estímulo no processo de reflexão dos laços entre metrópole e colônia, em que predominou a visão local da experiência colonial. ${ }^{2}$

Já sobre o sentido mais geral do fenômeno acadêmico na Europa das Luzes, a historiadora Ana Rosa Cloclet da Silva destaca a importância do pertencimento a esses espaços. O pensar os "problemas das nações no âmbito científico e técnico", em um locus institucionalizado do saber, atribuía seriedade profissional a essa elite intelectual, que acabava por se tornar uma ponte profícua no diálogo entre o governo e a sociedade, já que era a eles que se "dirigiam os governos na busca de conselhos, sugestões e pareceres". Para a autora, o fato de as academias serem calcadas em um conhecimento pragmático que "proporcionava a conexão entre os diversos ramos da ciência, articuladamente ao desenvolvimento tecnológico e de ensino" elevava-as "à condição de peça fundamental de uma sociedade que se pretendia progressiva e dinâmica". ${ }^{3}$

No que concerne especificamente ao universo letrado português, as principais bases da ilustração portuguesa tiveram como vertente a supremacia do caráter pragmático e experimental do conhecimento: na prática, houve uma clara valorização do Estado português para as Ciências Naturais. ${ }^{4}$ Nesse particular nos interessa ressaltar o sentido da reforma pedagógica de vanguarda empreendida por Pombal, especificamente à valorização do conhecimento militar. Nesse sentido, destacamos a criação do Colégio dos Nobres (1761) e a reforma da Universidade de Coimbra (1772), cuja orientação também privilegiou as ciências naturais e a experimentação, primando pela educação dos quadros militares do Reino. Enquanto o estatuto do Colégio dos Nobres enfatizava a importância das disciplinas de Arquitetura Militar, Arquitetura Civil e Desenho, a Universidade de Coimbra criava as

\footnotetext{
${ }^{1}$ Pesquisa financiada pela Fundação de Amparo à Pesquisa do Estado de São Paulo (FAPESP).

2 KANTOR, Iris. Esquecidos e Renascidos: historiografia acadêmica luso-brasileira (1724-1759). São Paulo: HUCITEC/Centro Estudos Baianos, 2004. p.16.

3 SILVA, Ana Rosa Cloclet da. Inventando a Nação: intelectuais ilustrados e estadistas luso-brasileiros no crepúsculo do Antigo Regime Português: 1750-1822. São Paulo: Hucitec/Fapesp, 2006. p.111.

${ }^{4}$ Sobre a discussão acerca da ilustração luso-brasileira, ver: DIAS, Maria Odila da Silva. "Aspectos da Ilustração no Brasil". Revista do Instituto Histórico e Geográfico Brasileiro. Rio de Janeiro: v. 278, 1968; NOVAIS, Fernando. "O reformismo ilustrado luso-brasileiro: alguns aspectos". In: Aproximações: estudo de história e historiografia. São Paulo, SP: Cosac Naify, 2005.
} 
faculdades de Matemática e Filosofia Natural "entre outros objectivos, para desenvolver as aptidões dos oficiais da Tropa de Linha, nomeadamente os engenheiros". ${ }^{5}$

Em relação ao caráter prático das reformas pedagógicas, foi notória a ênfase dada à Faculdade de Matemática. Segundo os estatutos, ao aprimorar o entendimento preciso da natureza, a matemática conduzia o Homem para uma atuação mais patente no processo de transformação do "grande número de artes úteis e necessárias ao Estado", o que significava regular "as épocas e medidas do tempo; as situações geográficas dos lugares; as demarcações e medidas do terreno; as manobras e derrotas dos pilotos; as operações táticas de campanha e de marinha; as construções de arquitetura naval, civil e militar". Isso englobava precisamente o aperfeiçoamento das "máquinas, fábricas, artifícios e aparelhos que ajudam a fraqueza do homem a executar o que d'outra sorte seria impossível às suas forças". 6 Para o sucesso de tal empreitada, portanto, era necessário que o Estado promovesse a formação de "matemáticos insignes", para que estes fossem empregados de forma proveitosa no Real Serviço. ${ }^{7}$ A valorização da Matemática como ciência de primeira ordem tinha um caráter político muito preciso: elevar Portugal entre as nações de maior relevo da Europa. Para tal intento, era fundamental a introdução de espaços de experimentação vinculados a esses dois cursos superiores. Dessa forma, um observatório astronômico, um museu de história natural, um gabinete de física, um laboratório químico e um jardim botânico passaram a fazer parte da nova realidade educacional.

Se, de forma mais geral, a reforma pedagógica pombalina visava a um maior diálogo cultural de Portugal em relação à Europa do Norte através de medidas modernizadoras que viabilizassem a laicização do conhecimento; na prática, contudo, manteve-se presente a forte conexão entre Universidade, Igreja e Estado, nitidamente expressa na influência eclesiástica no quadro de professores da Universidade de Coimbra. Para além dos avanços teóricos e do suporte científico, o iluminismo português exprimia um de seus principais paradoxos: manteve a religião como base de sustentação do absolutismo monárquico. Mesmo primando pela secularização do saber - com a expulsão dos jesuítas da direção das instituições educacionais no Império português -, as reformas pombalinas não permitiram, em última instância, a autonomização das instituições que formavam o aparelho do Estado. ${ }^{8}$

\footnotetext{
5 SILVA, Maria Beatriz Nizza da. Cultura luso-brasileira: da reforma da universidade à independência do Brasil. Lisboa: Editorial Estampa, 1999. p. 65.

6 PORTUGAL. Carta de lei de 28 de agosto de 1772. Dispõe sobre os Estatutos da Universidade de Coimbra. Lisboa, Regia Officina Typografica, 1772. [Parte referente à Faculdade de Matemática]. V. III, Segunda Parte, p. 142-143. Disponível em: http://scientia.artenumerica.org/estatutos_1772.html. Acesso em: 24/03/2012.

${ }^{7} I d$.

8 Para esta temática, ver: FILHO, Oswaldo M.; DAHÁS, Nashla. Acadêmicos e letrados na crise do Antigo Regime luso-brasileiro - Século XVIII. Revista Intellectus. V. I. 2006. Acesso em: 23/04/2012 e ARAúJO, Ana Cristina. "Dirigismo cultural e formação das elites no pombalismo", no qual ela demonstra o quanto o conteúdo das reformas é antijesuítico e antirromanismo, o que na prática revelou-se como uma defesa de uma moral mais austera e rigorista. Tal aspecto é um contraponto aos que defendem uma "modernização" encaminhada pelo reformismo pombalino. Disponível em:
} 
No período josefino, o centro das reformas educacionais esteve atrelado primordialmente à Universidade de Coimbra. Já durante o governo de D. Maria I - apesar da valorização destinada ao espaço -, a rainha voltou sua política educacional prioritariamente para a estruturação e o funcionamento da Academia das Ciências de Lisboa, a partir de 1779, espaço eleito pelos ilustrados como o locus de saber onde a aliança entre ciência e política se faria presente. A academia foi a instância articuladora da ilustração portuguesa, agora fortalecida nas suas tendências pragmática e cientificista através da produção de uma literatura memorialista e políticas fomentistas para o Reino e o ultramar, cuja peculiar associação entre saber e poder, daria o tom do reformismo do final do Setecentos. ${ }^{9}$

De fato, a política reformista da Coroa, no período mariano, esteve muito preocupada com os espaços de educação e se fez sentir nos dois lados do Atlântico. Durante o último quartel do século XVIII, instituições pedagógicas de caráter mais geral tiveram destaque, tais como a criação da Aula de Debuxo e Desenho, no Porto (1779), a Real Casa Pia de Lisboa, no Colégio de São Jorge (1782).

Criada por Pina Manique, a Casa Pia era um conjunto de colégios educacionais e de beneficência dirigido e administrado pelo intendente, com o objetivo de formar, sobretudo, homens eminentes e úteis ao país. Quando Pina Manique deixou de ser intendente de polícia (1803), a Casa Pia declinou sensivelmente, sendo extinta no tempo dos franceses. Dentre os principais estabelecimentos, destacamos: o Colégio de S. Lucas em Lisboa e outro, em Coimbra (filial do de Lisboa); o Recolhimento da Rainha Santa Isabel, que sustentava e educava órfãs desamparadas; o Colégio de Santa Margarida de Cortona, casa de correção de mulheres, e outro, para a correção e o doutrinamento de rapazes libertinos. Havia também uma casa de correção para mendigos de um e de outro sexo e um laboratório químico, onde se fabricavam gratuitamente remédios para os pobres. Nesse contexto educacional, portanto, a Casa Pia também aparece como um importante exemplo do "paradoxo" da ilustração portuguesa. ${ }^{10}$

No que concerne ao ensino militar ou das ciências da guerra, em Portugal era criada a Aula de Engenharia e Estudos Matemáticos da Academia Real da Marinha (1779), cujo objetivo era aprimorar a formação dos oficiais da armada em ciências matemáticas e astronômicas. Três anos mais tarde, institucionalizava-se a Academia Real dos Guardas-Marinha (1782), destinada "a formação dos oficiais 'hábeis e instruídos para a Armada Real'"; ${ }^{11}$ onze anos depois, em 1790, surgia a Academia de Fortificação, Artilharia e Desenho. Segundo João Ferreira Campos, esse espaço proporcionou ao oficialato português a instrução suficiente para

<https://digitalis.uc.pt/en/livro/dirigismo_cultural_e_forma\%C3\%A7\%C3\%A3o_das_elites_no_pombalis mo>. Acesso em: 19/05/2016.

$9 \quad$ SILVA. Op. cit., p. 113.

10 Pina Manique (Diogo Inácio da). Dicionário Histórico - Portugal. Disponível em: <http://www.arqnet.pt/dicionario/pinamanique.html>. Acesso em: 31/08/2011.

11 NEVES, Lúcia Bastos Pereira das; DUARTE, Eliane. "Academia Real dos Guardas-Marinha". In: NEVES; L. VAINFAS, R. (Org.). Dicionário do Brasil Joanino. Rio de Janeiro: Objetiva, 2008. p.22. 
"corresponder na parte militar às funções a que se destinavam". ${ }^{12} \mathrm{Em} \mathrm{1796,} \mathrm{nasciam} \mathrm{os}$ estatutos da Academia Real dos Guardas-Marinha, que elevavam a arte militar entre as mais úteis e necessárias ao Estado. Quanto às suas funções, destacavam-se as manobras e os percursos de pilotagem, operações práticas de campanha e da marinha, além da arquitetura naval e militar. ${ }^{13} \mathrm{Em} \mathrm{1792,} \mathrm{porém,} \mathrm{a} \mathrm{congênere} \mathrm{americana} \mathrm{da} \mathrm{Real} \mathrm{Academia} \mathrm{da} \mathrm{Artilharia,}$ Fortificação e Desenho de Lisboa passava a existir, no Rio de Janeiro, para instruir as milícias e os soldados.

Ao analisar a relevância dos engenheiros militares e arquitetos para a Coroa portuguesa durante toda a colonização (1500-1822), a pesquisadora Beatriz Bueno destaca a importância dada ao desenho que, segunda ela, certamente eram feitos em mais de uma via: uma, que se destinava aos conselhos ministeriais, e outra, que seguia com os profissionais para melhor orientar o trabalho dos mestres de ofício. "O investimento na ciência do desenho (i.e., ciência do projeto) no âmbito das Aulas de Arquitetura Militar era, portanto, fundamental, tendo-se constituído num dos mais importantes instrumentos de uma ação política [da Coroa portuguesa]."14

A despeito da ampla importância das manobras militares ocorridas em Portugal, no início do século XIX, interessa-nos discutir o sentido da figura do militar luso-brasileiro e do fomento governamental para a constituição de instituições militares que visassem, em última instância, à sustentação do Império português, sediado, a partir de 1808, do lado americano do oceano. Mesmo sem invasões ou perigo iminente de guerra a valorização da educação e o preparo militar do Estado eram pautados no princípio abstrato de autoridade e soberania. ${ }^{15}$ No universo científico português, sob os auspícios de D. Rodrigo de Sousa Coutinho, também podemos destacar a fundação da Sociedade Real Marítima, Militar e Geográfica para o Desenho, Gravura e Impressão das Cartas Hydrográficas, Geográficas e Militares, em 1798. ${ }^{16}$ No Rio de Janeiro, a criação do Real Observatório (1780) montado pelos astrônomos portugueses Sanches d'Orta e Oliveira Barbosa é uma referência importante. Ali se realizavam observações regulares de astronomia, meteorologia e magnetismo terrestre. Com a chegada da Coroa, em 1808, o acervo foi incorporado pela Real Academia Militar, o que corrobora ainda mais para a compreensão do amplo viés científico do locus de saber.

\footnotetext{
12 CAMPOS, João Ferreira. "Apontamentos relativos à instrução pública". In: MARQUES, Fernando Pereira. Exército e Sociedade em Portugal no declínio do Antigo Regime e advento do liberalismo. Lisboa: A Regra do Jogo, 1981. p. 12.

13 Neves; Duarte. Op. cit., p. 23.

14 BUENO, B. Desenho e Desígnio: o Brasil dos engenheiros militares (1500-1822). São Paulo: EDUSP/fapesp, 2011. p. 137-138.

15 MARQUES. Op. cit., p. 42.

16 Para a temática, ver: KANTOR, Iris. Mapas em trânsito: projeções cartográficas e processo de emancipação política do Brasil (1779-1822). Araucária: Revista Iberoamericana de Filosofía, Política y Humanidades. Año $12, \quad$ n. 24, $2010 . \quad$ Disponível em: http://www.institucional.us.es/araucaria/nro24/monogr24_4.pdf. Acesso em: 19/05/2016 e SANTOS, Nívia Pombo Cirne dos. Dom Rodrigo de Sousa Coutinho: pensamento e ação político-administrativa no Império Português (1778-1812). Dissertação (Mestrado em História). Universidade Federal Fluminense, Niterói, 2002.
} 


\section{A chegada da família real ao Brasil e a reestruturação militar da nova capital imperial}

A travessia atlântica da Corte portuguesa para o Brasil teve consequências expressivas. Se, por um lado, significava a chance de a monarquia portuguesa salvaguardar a integridade política da Coroa e tentar manter vivo o sistema absolutista, em crise eminente desde o final do século XVIII; por outro, aos olhos dos portugueses que ficaram no país e enfrentaram as três invasões francesas e, posteriormente, o domínio do exército inglês, a transladação da família real não deixava de ter um certo caráter de humilhação política. ${ }^{17}$

Para a Coroa portuguesa, no entanto, a travessia esteve vinculada a um projeto político administrativo do Império português cujas raízes remontam aos debates do século XVI. ${ }^{18} \mathrm{~A}$ transladação da monarquia, no início do século XIX, também objetivava atingir metas culturais mais amplas, as quais o historiador Afonso Carlos Marques dos Santos denominou de "projeto civilizatório", cuja principal finalidade era a ocidentalização, que comportava tanto "a importação de padrões civilizatórios europeus como uma tentativa de inserir esta parte do mundo no Ocidente", transformando o Rio de Janeiro em um autêntico laboratório de civilização sob a perspectiva de uma Europa possível. ${ }^{19}$

Apesar da invasão napoleônica, D. João manteve a Coroa e a Dinastia de Bragança no poder e, de qualquer modo, mesmo na América, conservou o seu reinado, a corte e a sede do governo. Para tristeza e possível humilhação dos súditos reinóis, o regente encontrava-se no ultramar.

Ademais, se a residência do rei europeu na América era uma absoluta novidade, a constituição de uma nova corte no Rio de Janeiro à imagem e semelhança de Lisboa, tampouco deixava de sê-lo. Construir uma corte saudável, policiada e, em última instância, civilizada, era, portanto, tarefa das mais importantes. ${ }^{20}$ Tal é o fato que, já em maio de 1808 , o príncipe

17 ANSART, Pierre. "As Humilhações Políticas". In: MARSON; NAXARRA (Org.). Sobre a humilhação: sentimentos, gestos, palavras. Uberlândia: EDUFU, 2005. p. 15-30.

18 Há uma bibliografia muito vasta sobre o período joanino que engloba os mais diferentes assuntos. Entre as obras clássicas, citamos: LIMA, Oliveira. D. João VI no Brasil. 3. ed. Rio de Janeiro: Topbooks, 1996; ALEXANDRE, Valentim. Os sentidos do Império: questão nacional e questão colonial na Crise do Antigo Regime Português. Lisboa: Edições Afrontamento, 1993; LYRA, Maria de Lourdes Viana. A utopia do poderoso império: Portugal e Brasil: bastidores da política (1798-1822). Rio de Janeiro: Sete Letras, 1994. Uma importante discussão historiográfica sobre a contribuição das obras referentes ao período joanino (1809-1821) pode ser encontrada em: CASTRO, Giovanna Milanez de. O Palco da realeza: as transformações no espaço urbano e nas práticas sociais no Rio de Janeiro (1808-1821). Monografia. 2012, p. 15-41. (Orientação: Prof. ${ }^{a}$ Dr. ${ }^{a}$ Leila Mezan Algranti). Sobre o debate historiográfico recente e as principais obras que vieram a público em 2008, devido ao bicentenário da chegada da Corte portuguesa ao Brasil, ver: LUSTOSA, Isabel. "O período joanino e a eficiência de alguns textos desbravadores". Disponível em: <http://www.casaruibarbosa.gov.br/dados/DOC/revistas/Escritos_2/FCRB_Escritos_2_16_Isabel_Lustosa .pdf. >. Acesso em: 19/05/2016.

19 SANTOS, Afonso Carlos Marques dos. "A fundação de uma Europa possível". In: Seminário Internacional D. João VI: um rei aclamado na América. Rio de Janeiro, Museu Histórico Nacional, 2000, p. 9-10.

20 CARVALHO, Marieta Pinheiro de. Uma ideia de cidade ilustrada: as transformações urbanas no Rio de Janeiro de D. João VI (1808-1821). Rio de Janeiro: Odisseia, 2008. p. 102. 
regente revelava: "[...] onde eu existo, e resido é que necessariamente se deve considerar a sede, e ponto central do Império". ${ }^{21}$ A declaração de D. João aos seus governadores do Reino demarcava uma mudança fundamental de perspectiva política: o Reino perdera o seu papel de nexo da unidade imperial e a questão da capitalidade do Império português aparecia na cena pública. ${ }^{22}$ Neste novo cenário, a constitução de uma real academia militar era digna de todas as atenções e esforços.

O início do processo das modificações urbanas no Rio de Janeiro ocorreu simultaneamente à reestruturação burocrática do Estado. Particularmente em relação ao universo administrativo, foi criado o Conselho Militar e da Justiça (1808), que ficava responsável por todas as matérias que pertenciam ao Conselho de Guerra, ao Almirantado e aos assuntos do ultramar, no que referia somente à parte militar. Como já salientou Maria de Fátima Gouvêa, o Rio de Janeiro tornou-se a cabeça de comando das forças e dos assuntos militares que diziam respeito ao Estado do Brasil. ${ }^{23}$

Nesse contexto, não nos soa nada estranho a criação, pelo príncipe regente, do Arquivo Real Militar, destinado a preservar os mapas e as plantas de fortalezas, baterias e artefatos de guerra já existentes no Brasil, ${ }^{24}$ passado exatamente um mês da chegada da Coroa no Rio de Janeiro. Entre as funções do espaço destacava-se a conservação "em bom estado de todas as cartas gerais, particulares, geográficas ou topográficas" existente em todo o território brasileiro e demais domínios ultramarinos. ${ }^{25}$ O Arquivo estava diretamente subordinado ao Ministério dos Negócios Estrangeiros e da Guerra, sendo também dependente do Erário Régio e da Secretaria dos Negócios da Marinha e Domínios Ultramarinos. O diretor da instituição era responsável por todo o acervo e os demais planos militares em execução pelos engenheiros do espaço (como os planos de fortalezas, fortes e baterias, ou ainda todos os projetos de estradas, navegações de rios, canais, portos etc.) que, porventura, Ihes fossem confiados. O regimento ainda previa que todos os funcionários empregados no Arquivo ficariam "ligados ao maior segredo em tudo o que de sua natureza assim o exigir", tendo nas mãos a responsabilidade de todas as matérias ali desenvolvidas. De início, a direção do espaço coube

\footnotetext{
${ }^{21}$ ANTT. Série Ministério do Reino. Registro de Ordens expedidas pelo Príncipe Regente aos governadores do Reino. Livro 380.

22 Para a compreensão do papel do Brasil dentro do Império português, ver: DIAS, Maria Odila da Silva. A interiorização da Metrópole (1808-1853). In: MOTTA, Carlos Guilherme (Org.). 1822: Dimensões. São Paulo: Ed. Perspectiva, 1972; LYRA, Maria de Lourdes Viana. A utopia do poderoso império. Portugal e Brasil: bastidores da política (1798-1822). Rio de Janeiro: Sette Letras, 1994; BICALHO, Maria Fernanda. O Rio de Janeiro no século XVIII: a transferência da capital e a construção do território centro-sul da América Portuguesa. Disponível em: www.ifch.unicamp.br/ciec/revista/artigos/dossie1.pdf; SCHULTZ, Kirsten. Versalhes Tropical: império, monarquia e a Corte Real portuguesa no Rio de Janeiro, 1808-1821. Trad.: Renato Aguiar. Rio de Janeiro: Civilização Brasileira, 2008.

23 GOUVÊA, Maria de Fátima. As bases institucionais da construção da unidade. Dos poderes do Rio de Janeiro joanino: administração e governabilidade no Império luso-brasileiro. In: JANCSÓ, István (Org.). Independência: história e historiografia. São Paulo: Hucitec/Fapesp, 2005. p. 707-752.

24 Para informações mais detalhadas sobre o Real Arquivo Militar, acessar a Memória da Administração Pública Brasileira (MAPA), um projeto do Arquivo Nacional do Rio de Janeiro. Disponível em: http://linux.an.gov.br/mapa/?p=2788.

25 Regimento do Arquivo Militar presente no Decreto de 07 de abril de 1808. Disponível em: http://www.planalto.gov.br/ccivil_03/revista/Rev_23/dec_7abril.htm. Acesso em: 02/06/2012.
} 
a Henrique Isidoro Xavier de Brito, sargento-mor e engenheiro da Corte. ${ }^{26} \mathrm{O}$ regimento real reiterava a importância que a Coroa destinava à conservação dos documentos oficiais, sobretudo os referentes à defesa e ao progresso urbano do território. O espaço contaria com a presença de engenheiros e desenhadores, cuja principal incumbência era examinar "as cartas das diversas capitânias e territórios do Brasil" para exporem "o seu juízo sobre a autenticidade e exatidão das mesmas ou sobre a necessidade de serem corrigidas ou levantadas de novo". ${ }^{27}$ Nesse sentido, desde o início, a monarquia bragantina já expunha a preocupação com a constituição de um novo império do lado americano do Atlântico. ${ }^{28}$

No período colonial, a opção de a monarquia portuguesa constituir, nesse lado do Atlântico, uma academia científica com viés militar demonstra a viva preocupação não apenas com a educação científica de seus súditos de além-mar, mas também com a valorização da segurança da capital colonial. ${ }^{29}$ Segundo Maria Fernanda Bicalho, desde o século XVI, a cidade do Rio de Janeiro fora alvo de "um intenso assédio por parte dos corsários e contrabandistas", o que reiterava a iniciativa real em "encerrá-la sob fortalezas, trincheiras e muralhas" através da ação de funcionários e engenheiros militares cuja função se concentrava principalmente no levantamento de plantas urbanas e no desenho de mapas das várias capitanias. ${ }^{30}$ Essa estratégia fazia parte do projeto reformista da Coroa portuguesa, cuja política cultural, além de ter a pretensão de formar súditos fiéis e militarmente preparados para a defesa da colônia, mantinha a continuidade do processo de fomento educacional de viés científico, agora com um locus de cultura destinado exclusivamente a tais aprendizados e reflexões.

Em 1795, houve um desdobramento da Academia de Artilharia, criada três anos antes, que passou a ser denominada Academia de Aritmitética, Geometria Prática, Fortificação, Desenho e Língua Francesa. ${ }^{31} \mathrm{O}$ novo espaço seria voltado exclusivamente para o preparo dos oficiais da arma de Infantaria. De acordo com Adailton Pirassununga, essa mudança ocorreu

26 PONDÉ, Francisco. Academia Real Militar. In: Anais do Congresso da Independência do Brasil. Rio de Janeiro, IHGB, 1975, p.50.

27 Regimento do Arquivo Militar presente no Decreto de 07 de abril de 1808. Disponível em: http://www.planalto.gov.br/ccivil_03/revista/Rev_23/dec_7abril.htm. Acesso em: 02/06/2012.

28 LYRA, Maria de Lourdes Viana. A utopia do poderoso império. Portugal e Brasil: bastidores da política (1798-1822). Rio de Janeiro, Sette Letras, 1994.

29 O historiador português Rogério Fernandes faz uma importante discussão sobre as diferentes vertentes do Iluminismo português em relação à educação científica. FERNANDES, ROGÉRIO. Os caminhos do ABC: Sociedade Portuguesa e o Ensino das Primeiras Letras. Porto: Porto Editotora, 1994, p. 122-165.

30 BICALHO, Maria Fernanda. O Rio de Janeiro no século XVIII: A transferência da capital e a construção do território centro-sul da América portuguesa. Revista Eletrônica do CIEC 1.1. URBANA v.1, 2006. Disponível em: http://www.ifch.unicamp.br/ojs/index.php/urbana/article/view/1046. Acesso em: $12 / 04 / 2013$.

31 As principais bases e diretrizes da Real Academia da Artilharia, Fortificação e Desenho do Rio de Janeiro foram circunscritas no estatuto de 17 de dezembro de 1792 . De autoria do vice-rei da colônia, o conde de Rezende, o documento proclamava ser a instrução dos discípulos o objetivo do novo locus de saber. Ao circunscrever o ataque e a defesa como linhas mestras do ensino da nova Academia, o vice-rei expunha a principal vinculação teórica do estabelecimento: a inspiração em Belidor, Sam Remy e le Blond, matemáticos europeus de grande destaque e influência da época, o que demonstrava o vivo interesse da Coroa em estimular o conhecimento científico de ponta tendo como finalidade última a prática e a experimentação. Os Estatutos da Real Academia da Artilharia, Fortificação e Desenho, da Cidade do Rio de Janeiro foi transcrito pelo pesquisador Adailton Pirassununga em: PIRASSUNUNGA, Adailton Sampaio. O Ensino Militar no Brasil. Rio de Janeiro: Biblioteca do Exército, 1958. 
pela não adaptação dos alunos àquele meio, os quais tinham dificuldade com o aspecto abstrato da disciplina de Geometria e Fortificação.

[Foi] diminuto o proveito colhido pelos mesmos [alunos] que se escusavam de fazer a aplicação conveniente, seja pelos assuntos tratados na referida aula serem mais próprios aos oficiais de Artilharia, seja pelo pouco tempo que Ihes restava, satisfazendo às obrigações do serviço diário do regimento. ${ }^{32}$

O espaço funcionou até 1811 , quando foi definitivamente substituído pela Real Academia Militar.

Tal escolha político-dministrativa marcava uma rearticulação das bases de sustentação de seu poder sob uma perspectiva transatlântica, o que justificava a declaração de guerra ao imperador francês e seus vassalos tão logo a Coroa estivesse a salvo, fato que realmente ocorreu em 10 de junho de 1808. Do Rio de Janeiro, D. João ordenava que "por mar, e por terra se Ihes façam todas as possíveis hostilidades" contra a nação francesa. ${ }^{33}$ Nessa posição, o príncipe regente deixava clara a sua ciência de que a regeneração do Estado português perpassava, necessariamente, pelo enfrentamento de uma guerra contra Napoleão pelas duas margens do Atlântico. Se em Portugal o foco da atuação política e militar visava à expulsão dos inimigos do território lusitano, o que significaria a salvação e independência do Reino, no Brasil era mister construir uma estratégia eficiente de defesa de tão vasto continente e parte fundamental do Império, como apregoava D. Rodrigo de Sousa Coutinho desde 1803, para que a monarquia portuguesa se mantivesse a salvo. ${ }^{34}$ Como bem circunscreveu Maria de Fátima S. Gouvêa, "Munições militares e literárias eram instrumentos básicos em uma corte europeizada, cabeça de uma totalidade política e territorial muito mais ampla, como a do Império português, então reconstituído como Império luso-brasileiro" (grifo do original). ${ }^{35}$ Para atingir tal intento, a estruturação de uma ampla base beligerante deste lado do Atlântico era intrínseca ao funcionamento de diversas instituições reais. Aqui, particularmente, interessa-nos referir três importantes instituições que passaram a vigorar no Rio de Janeiro: a Impressão Régia, a Intendência Geral da Polícia e a própria Real Academia Militar, conforme discutiremos adiante.

\footnotetext{
${ }^{32}$ Id., p. 43.

33 "Declaração de guerra aos franceses". ANRJ. Tribunal do Desembargo do Paço Cx. 231, pct. 1. Doc. 1.

34 A preocupação com a defesa da colônia e a importância das aulas de arquitura militar em todo o território foi patente desde o final do século XVII, quando a Coroa lusitana institucionalizou estes espaços nos principais centros urbanos, a saber: Salvador (1696), Rio de Janeiro (1698-1699), São Luís do Maranhão (1699), Recife (1701) e Belém (1758).

35 GOUVÊA. Op. cit., p. 726.
} 


\section{A Real Academia Militar do Rio de Janeiro e a política imperial lusitana}

A partir de 1808, a monarquia portuguesa rearticulou as bases de sustentação do Império português repensando a importância das diversas instituições de caráter cultural no espaço público. É dentro desse cenário de conturbada transição política que a instauração da Real Academia Militar do Rio de Janeiro, em 1810, situa-se como um dos principais locus de cultura de viés científico instaurado durante o governo de D. João no Brasil (1808-1821) para a sustentação do Império português pelas duas margens do Atlântico. A vigência desse espaço, ao longo do período joanino, foi indissociavél da constante atuação da Intendência Geral da Polícia e do apoio incondicional da Impressão Régia, duas instituições centrais nesse processo. $^{36}$

Em um contexto em que a segurança da nova capital aparecia como preocupação de primeira grandeza, não nos causa espanto o grande número de ordens e regulamentos reais referentes ao universo militar, geralmente divulgado na Gazeta do Rio de Janeiro. Em 1816, por exemplo, um anúncio informava aos moradores da Corte que estes podiam encontrar na Loja da Gazeta as seguintes obras: Regulamentos do Ex.mo Beresford, Regulamento de Infantaria, Dito de Cavalaria, Dito de Caçadores, Dito de Milicianos, Regulamento para o Exército de Portugal, Dito de Ordenanças, Prática para os Conselhos de Guerra, Máximas da Guerra e Instruções Militares, Privilégios dos Milicianos. O mesmo aviso ainda colocava à disposição do público "um grande sortimento de livros Militares tanto em Português como em Francês" (grifos do original). ${ }^{37}$ Nesse sentido, é imprescindível destacar que a ação governamental perpassava um amplo campo de reordenação política e militar: do recrutamento das tropas à administração dos recursos materiais necessários para a manutenção dos corpos militares, é patente a atuação dos homens fortes do governo joanino, com destaque para a figura do ministro dos Negócios Estrangeiros e da Guerra e o intendente da Polícia (Paulo Fernandes Viana). ${ }^{38}$ Enquanto ao primeiro ficava o cargo de "centralizar a operacionalização das relações externas da Corte Portuguesas (sic), a partir da sede

\footnotetext{
36 A prática cotidiana do universo político situava a governabilidade da nova capital intrinsecamente associada aos órgãos encarregados da gestão do Império. Nesse processo de profunda reordenação política, destacamos a Impressão Régia e a Intendência Geral da Polícia como duas instituições de grande relevo. Sob a direção de Paulo Fernandes Viana, a Intendência da Polícia foi responsável pela obtenção do sucesso da guerra travada contra Napoleão Bonaparte, ficando encarregada de controlar a ordem, administrar as obras públicas e organizar as tropas na Corte e tinha, entre outras funções, de constituir a Guarda Real da Polícia (responsável pelo patrulhamento da cidade), além de vigiar e controlar a entrada de estrangeiros (sobretudo franceses e espanhóis). Já aos diretores da Impressão Régia cabia imprimir exclusivamente toda a legislação e os papéis diplomáticos, que emanassem de qualquer repartição do real serviço. A Tipografia Real primava pela divulgação e circulação das ordens reais nos dois lados do Atlântico, tornando público os papéis oficiais. Dessa forma, o monarca emanava para todo o corpo social as diretrizes políticas adotadas pelo governo, fossem essas de aliança política e/ou militar ou mesmo de guerra contra o inimigo. Convém não esquecermos que a Impressão Régia estava subordinada ao Ministério dos Negócios Estrangeiros e da Guerra.

37 Gazeta do Rio de Janeiro. 1816. n.90.

38 Para a lista completa dos 8 ministros da Secretaria de Estado dos Negócios Estrangeiros e da Guerra entre 1808 e 1821, ver: MARTINS, Ana Canas. Governação e Arquivos: D. João VI no Brasil. Lisboa, Instituto dos Arquivos Nacionais, 2007. p.428.
} 
brasileira"39, ao segundo era destinada a responsabilidade tanto pela organização da defesa militar quanto do abastecimento da cidade; uma articulação vasta e complexa que envolvia importantes atores históricos. ${ }^{40} \mathrm{Em}$ maio de 1810 , por exemplo, o governo decretava a criação de novos regimentos de Milícias de Caçadores de Henriques na Corte, atitude que contou com o grande esforço empreendido por Paulo Fernandes Viana. No bojo dessas transformações se estruturou e vigorou a Real Academia Militar no período joanino.

O decreto real de 4 de dezembro de 1810 especificava as razões de uma corte imperial possuir uma academia militar. Dentre elas, sobressaía o estabelecimento no Brasil (e na atual Corte real e cidade do Rio de Janeiro) de "um curso regular das Ciências exatas, e de Observação, assim como de todas aquelas que são aplicações das mesmas aos Estudos Militares e Práticos, que formam a Ciência Militar em todos os seus difíceis e interessantes ramos". Sob esse prisma, objetivavam a formação de

[...] hábeis oficiais de Artilharia, Engenharia e ainda mesmo Oficiais da classe de Engenheiros Geógrafos e Topógrafos, que possam também ter o útil emprego de dirigir objetos administrativos de Minas, de Caminhos, Portos, Canais, Pontes, Fontes e Calçadas. ${ }^{41}$

A constituição da Real Academia Militar era parte integrante do projeto reformista de D. Rodrigo de Sousa Coutinho, que voltava à cena política com grande evidência. Sua nomeação para o comando do Ministério dos Negócios Estrangeiros e da Guerra não apenas reiterava a predominância das diretrizes ideológicas vigentes do partido inglês como também impunha aos demais homens de Estado - como, por exemplo, seu arqui-inimigo Antonio de Araújo e Azevedo - a preponderância de seus projetos políticos. Pelo prisma ideológico de Sousa Coutinho, a segurança dos domínios imperiais, o bem público de todo o corpo social e a formação intelectual dos súditos compunham o tripé fundamental que justificava a criação de uma academia militar na nova corte; sobretudo, em tempos de guerra declarada contra a França napoleônica.

Se era imperativa a constituição de homens hábeis na arte da guerra (como apregoava o título VIII do Decreto de 1810), também era indispensável que a nova corte formasse engenheiros, geógrafos e topógrafos que viabilizassem - com sucesso - seu projeto político reformista: a gênese do Império luso-brasileiro, um empreendimento audacioso que ganhava tonalidades reais a partir de 1808. Por essa vertente, portanto, as bases do estatuto da Real Academia Militar representavam com clareza o ideário reformista de Linhares, que dialogava de perto com a tendência da época de profissionalização e burocratização da carreira militar. Dentro dos saberes, a "Arte da Guerra" aparecia como uma importante ciência a ser aprimorada. Como bem contextualizou a historiadora Elaine Duarte, foi a partir de 1800 que as

\footnotetext{
${ }^{39}$ Id., p. 130.

40 GOUVÊA. Op. cit., p. 730-731.

41 Carta de lei de 4 de dezembro de 1810. Dispõe sobre a criação da Academia Real Militar do Rio de Janeiro. Disponível em: http://www2.camara.leg.br/legin/fed/carlei/anterioresa1824/cartadelei-40009-4dezembro-1810-571420-norma-pe.html. Acesso em: 10/06/2012.
} 
academias militares na Europa e na América perderam o seu caráter rudimentar e tornaram-se "espaços específicos para a formação da oficialidade, contando para isso com o avanço e desenvolvimento da guerra". 42

Já de início, o Decreto de 1810 colocava em foco a estrutura hierárquica de poder do novo lugar de ensino, que seria dirigido por uma junta militar, que deveria ser composta por cinco oficiais do exército de alta patente. O Decreto de 11 de março, no entanto, não seguia à risca as determinações originais. Ao instituir apenas três militares para a direção da academia, o príncipe regente determinava que "não obstante não Nomear Eu por ora outros Deputados de que se deve compor-se a Junta, haja ela de reunir-se desde logo e ter suas sessões e exercícios que Ihe compete pela sobredita Carta de Lei de sua instituição". ${ }^{43}$ Foram então nomeados os seguintes militares: tenente-general Carlos Antonio Napion, no cargo de presidente; o brigadeiro João Manuel da Silva, no cargo de primeiro deputado e diretor do Real Arquivo Militar; o coronel Manoel Jacinto Nogueira da Gama, no cargo de segundo deputado. Ao longo do período, fizeram parte da Junta os seguintes súditos: Francisco da Borja Garção Stockler, que sucedeu a Carlos A. Napion, por conta de seu falecimento, em 1815; o marechal Joaquim de Oliveira Álvares (nomeado em 1820) e, por fim, o comandante do Corpo de Engenheiros e diretor do Arquivo Militar, o brigadeiro Joaquim Norberto Xavier de Brito, a partir de abril de 1821.

A academia também contaria com 11 lentes e cinco substitutos responsáveis por ministrar as diversas disciplinas que contemplavam a grade curricular do Curso Militar dividido em sete anos. Ser professor da Real Academia era um posto de alta consideração dentro da sociedade de corte. Como súditos que compunham a seleta órbita da elite ilustrada, eram detentores de "distintas luzes" sendo, por isso, dignos de serem escolhidos pela Junta Militar. Se o mérito da formação acadêmica aparecia como um dos atributos principais nesse processo de seleção, a fidelidade à monarquia tinha igual peso. Isto é, valorizavam-se muito as ações e os projetos militares que esses homens desempenhavam dentro do Império português, o que os colocava em uma posição hierárquica privilegiada: na corte joanina eram vistos como súditos fiéis que foram reconhecidos pelo monarca como tal. Ressaltava o estatuto, em uma clara valorização dos feitos militares da vida cotidiana como atitude de distinção:

Haverá toda consideração ao adiantamento dos oficiais, que forem lentes e que nos exercícios geodésicos e de reconhecimentos anuais e outros trabalhos militares tiverem feito ver que continuaram a praticar $\mathrm{e}$ distinguir-se no meu real serviço. ${ }^{44}$

\footnotetext{
42 DUARTE, Eliane. Da Real Academia à escola militar: a profissionalização das armas e a consolidação do ensino militar no Brasil (1810-1855). Dissertação (Mestrado em História). Universidade Estadual do Rio de Janeiro, Rio de Janeiro, 2004, p. 18.

43 Decreto de 11 de março de 1811 apud PONDÉ, Francisco de Paula e Azevedo. "Academia Real Militar". In: Anais do Congresso da Independência do Brasil. Rio de Janeiro: IHGB, 1975, p. 52.

${ }^{44}$ Id. Carta de lei de 4 de dezembro de 1810.
} 
Tal era o fato, que os lentes contavam as "mesmas honras e graças das Academias Militares da Marinha e Exército de Terra, na Cidade de Lisboa", recebiam $400 \$ 000$ réis anuais além do soldo da patente e ainda gozavam de uma prerrogativa muito especial: tinham os mesmos "privilégios, indultos e franquezas" dos mestres da Faculdade de Matemática da Universidade de Coimbra. ${ }^{45}$

Quanto às disciplinas que ministravam, estas eram assim distribuídas: Aritmética, Álgebra, Geometria, Trigonometria Retilínea e as primeiras noções da Esférica compunham a grade curricular do primeiro ano, que já primava por um ensino voltado às aplicações e aos experimentos. Especificamente sobre as fórmulas trigonométricas, estas deveriam ser ensinadas "procurando desenvolver aquele espírito de invenção, que nas ciências matemáticas conduz às maiores descobertas". No segundo ano, ensinava-se Álgebra, Geometria, Geometria Analítica, Cálculo Diferencial e Integral, Geometria Descritiva e Desenho. Nessa fase da instrução, o estatuto destacava a preocupação com a apreensão das ciências estudadas, "até onde têm chegado nos nossos dias nas brilhantes aplicações à Física, à Astronomia e ao Cálculo das Probabilidades". ${ }^{46}$

O terceiro ano priorizava o ensino da Mecânica, da Balística e do Desenho. Ao referir-se à obra do matemático e astrônomo inglês Olinto Gilberto Gregory (1774-1841) sobre a mecânica, o estatuto destacava que dela se deveria extrair "tudo o que toca às máquinas e suas aplicações, de que deverá fazer a explicação sobre as estampas e os modelos, que sucessivamente se irão fazendo construir para uso da mesma Escola". O quarto ano era voltado para a investigação da Trigonometria Esférica, da Física, da Astronomia, da Geodésia, da Geografia Geral e do Desenho. Sobre a mecânica celeste de Pierre-Simon Laplace (17491827), o lente deveria priorizar "os grandes resultados que ele tão elegantemente expôs e daí explicando todos os métodos às determinações das latitudes e longitudes no mar e na terra" a fim de mostrar aos discípulos "as aplicações convenientes às medidas Geodésicas, que novamente, dará em toda a extensão". ${ }^{47}$ Se os quatro primeiros anos do curso constituíam uma ampla base acadêmica de grau superior, os três últimos anos eram voltados exclusivamente para o estudo militar e de engenharia, que deveriam ser realizados em sua totalidade apenas por aqueles que desejassem obter o diploma de artilheiros e engenheiros. ${ }^{48}$

Do quinto ao sétimo ano, os alunos contavam com a presença de dois lentes. No quinto ano, um professor ficava responsável pelas disciplinas de Tática, Estratégia, Castrametação, ${ }^{49}$ Fortificação de campanha e reconhecimento do Terreno e o outro, pela docência da Química, estudada através de autores célebres como Antoine Lavoisier (1743 - 1794), considerado o pai da Química Moderna. No sexto ano, enquanto o primeiro docente ministrava Fortificação

\footnotetext{
45 Carta de lei de 4 de dezembro de 1810.

${ }^{46} I d$.

47 Ibid.

48 MOTTA, Jehovah. Formação do oficial do Exército. Rio de Janeiro: Companhia Brasileira de Artes Gráficas, 1976. p. 20.

49 "Arte de assentar acampamentos e fortificar". BUENO. Op. cit., p. 227.
} 
regular e irregular, ataque e defesa das praças, Arquitetura Civil, Estradas, Portos e Canais, o segundo lecionava Mineralogia e Desenho. Por fim, o sétimo ano contava com três disciplinas de grande importância para os engenheiros e militares: a Artilharia (Teórica e Prática) e Minas (que incluía o ensino da Geometria Subterrânea), ensinadas pelo primeiro lente, e História Natural, de responsabilidade do segundo docente. À época, o infante e o cavaleiro podiam ser formados em dois anos de estudo; um ano de Matemática Elementar e o outro, de Tática, Estratégia, Castrametação e Fortificação Passageira. Já os artilheiros e engenheiros, ao longo de sete anos de estudos, constituíam a nata intelectual do Exército, sendo os "cientistas" e os "doutores"50. O estatuto ainda previa a constituição de uma Biblioteca Científica e Militar, que teria como bibliotecário o professor responsável pelo magistério da "História Militar de todos os povos". Esta disciplina seria ministrada em um eventual oitavo ano.

A redação do estatuto foi feita pelo próprio conde de Linhares que, desde o final do século XVIII, alertava para a necessidade da formação de um contingente militar nas partes que constituem o todo para, assim, melhor defender o Império. De fato, uma das linhas mestras da política cultural joanina foi a circulação de informações oficiais pela imprensa periódica interatlântica e, consequentemente, a divulgação dos projetos políticos do governo monárquico na América através da arena pública. Essa prática justifica a posição de $D$. Rodrigo de Sousa Coutinho, em 1811, quando pediu aos redatores d'O Investigador Portuguez em Inglaterra para publicarem um artigo sobre a Real Academia Militar, considerada por ele, uma instituição próspera que correspondia perfeitamente ao olhar iluminado do príncipe regente. ${ }^{51}$

No ano seguinte, em abril de 1812, coincidentemente três meses depois da morte de Sousa Coutinho, ${ }^{52}$ os redatores $d^{\prime} O$ Investigador Portuguez publicavam uma longa reflexão sobre a importância de um estado soberano possuir uma academia militar: "[...] a história do género humano é a história de suas guerras, e a superfície habitável e inabitável do globo tem sido e continua a ser o teatro da sua luta", conclamavam. Ao constatarem que tal realidade era "uma triste e terrível verdade", defendiam que a independência do Estado era intrínseca ao aperfeiçoamento do sistema militar: "Armar-se pois, e aprender a brigar deve ser a eminente característica de toda a nação que quer ser livre e independente; ou por outras palavras a Instituição de uma escola militar deve ser um dos primeiros objetos d'atenção de um sábio legislador"; no caso, D. Rodrigo de Sousa Coutinho, homem "com requisitos mais que essenciais para a fundação de tal estabelecimento" já que este possuía "conhecimentos não superficiais das ciências, que tão magistralmente distribui no seu plano". ${ }^{53}$

O artigo desencadeou uma aguda polêmica com Hipólito da Costa no Correio Braziliense, o que deu ainda maior visibilidade a essa instituição régia. Ainda em abril de 1812,

\footnotetext{
50 MOTTA. Op. cit., p. 20

51 SILVA. Op. cit. , p. 263.

52 D. Rodrigo morreu no dia 26/01/1812, aos 56 anos de idade. Gazeta do Rio de Janeiro, 1812. n. 09.

53 O Investigador Portuguez, v. VIII, p. 272-275.
} 
Hipólito afirmava que Sousa Coutinho "não possuía os conhecimentos necessários, para formalizar o Plano de estudos para todas as ciências" e defendia veementemente que

[...] seria coerente com a dignidade do legislador, que o Conde de Linhares, havendo consultado os homens instruídos nestas matérias, os ajuntasse, Ihes mandasse dirigir, e arranjar o plano de estudos, e por uma lei $[\ldots]$ confirmasse e mandasse executar o plano formalizado pelos respectivos Professores. ${ }^{54}$

O jornalista ainda ressaltava o desserviço de Linhares ao propor um estabelecimento que fugia totalmente da sua competência política: o pedantismo da proposta era marcado, nomeadamente, pelo fato de o ministro nunca ter seguido a vida militar, além de ter circunscrito a administração da Junta Militar da Academia ao Ministério dos Negócios Estrangeiros e da Guerra, ou seja, sob a sua total direção.

Hipólito defendia a "não interferência do Estado na organização direta da instrução pública", considerando que a grade curricular e a conexão entre as disciplinas deveriam ser "assunto de especialista". ${ }^{55}$ Tal julgamento indica o olhar crítico do periodista, cuja influência iluminista era patente: os responsáveis por pensar a produção do conhecimento deveriam fazê-lo, antes, por mérito. As relações políticas, nesse sentido, necessariamente, ficariam em segundo plano. Por esse prisma, compreendemos o exame feroz de Hipólito para com as diretrizes governamentais joaninas de natureza absolutamente autoritária. Não podemos nos esquecer de que a polêmica entre O Investigador Portuguez e o Correio Braziliense teve como foco o debate acerca das bases da Carta Régia de 1810 e ocorreu entre os meses de abril e junho de 1812, momento em que findava a influência política de Linhares na governança do Império português. Apesar disso, a academia contava com nomes de grande destaque do universo letrado luso-brasileiro como Francisco de Borja Garção Stockler e Manoel Jacinto Nogueira da Gama, além de Wilhelm Ludwig Freiherr von Eschwege, o barão de Eschwege, todos muito próximos ao círculo político de D. Rodrigo de Sousa Coutinho. ${ }^{56}$ Por um prisma mais amplo, destarte, também podemos dizer que a discussão entre os periódicos girava em torno do sentido político de uma corte possuir uma academia militar. Segundo a historiadora Andrée Mansuy-Diniz Silva, a Real Academia Militar foi uma das grandes realizações de ordem científica e cultural durante a regência de D. João VI no Brasil. Tal consideração, segundo a autora, justifica-se, sobretudo, diante da concepção da instituição: ter como meta o preparo dos futuros líderes militares e políticos do Império luso-brasileiro. ${ }^{57}$

\footnotetext{
${ }^{54}$ Correio Braziliense, v. VIII, p. 488-489.

55 OLIVEIRA, José Carlos. Os periódicos portugueses de Inglaterra e a Cultura Científica Brasileira (18081821). Revista da SBHC, n. 19, 1998. p. 31-62.

56 Para mais informações sobre o tema, ver: CASTANHO, Sérgio, Educação e trabalho no Brasil Colônia. Disponível em: http://www.histedbr.fe.unicamp.br/navegando/artigos_pdf/Sergio_Castanho_artigo.pdf. Acesso em: 19/05/2016 e TELLES, Pedro Carlos da Silva. História da Engenharia no Brasil. Rio de Janeiro, RJ: Livros Técnicos e Científicos, 1984; TELLES, Pedro Carlos da Silva. Evolução Histórica da engenharia no Brasil. Revista do IHGB. RJ, n. 158, v. 397, p. 1-107, out./dez. 1997.

57 SILVA, A. Portrait d'unhomme d'État: D. Rodrigo de Sousa Coutinho, Comte de Linhares, 1755-1812.

Paris: Centre Culturel Calouste Gulbenkian, 2006, v. 1, p. 263.
} 
O debate público acerca da vigência de uma academia militar na nova sede do Império português também garantia a $D$. João e seus ministros um espaço importante dentro da lógica diplomática europeia; aos súditos reais, indicava o forte empenho da Coroa em manter seguros seus domínios territoriais ultramarinos; e, quanto aos países beligerantes do Velho Mundo (França e Inglaterra), divulgava a preocupação com o ensino militar e a formação de um exército nacional. Especificamente em relação à França, com a qual travava uma guerra pelas duas margens do Atlântico, expunha a atenção e o esforço empreendido para a obtenção da vitória contra Napoleão Bonaparte, mesmo que esta ocorresse mais através do plano simbólico. ${ }^{58}$ Possuir um locus de saber exclusivamente voltado para o universo militar e a arte da guerra significava, em última instância, preparar-se pelas armas contra qualquer tipo de ameaça externa.

Nesse espaço, a Coroa visava formar os homens de ciência do novo Império, cuja missão era contribuir para a formação de uma esfera pública de divulgação e debate de novos saberes que atravessariam o Atlântico delineando, simbolicamente, a força e independência da nação luso-brasileira. Como bem denominou Marco Morel ao estudar o perfil dos colaboradores d'O Patriota, naquele momento destacava-se, no Brasil, a figura do militar-cientista. Vinculados às atividades do Estado, esses homens "enquadravam-se nas formas vigentes dos espaços públicos, sem abrir mão, porém, de tentar reformá-los, pela propagação das luzes do saber e da ciência, por meio do ensino, da palavra impressa, e da atuação administrativa". ${ }^{59}$ Nesse cenário, destacamos o naturalista carioca João da Silva Feijó, que atuou como secretário do governo em Cabo Verde e foi, posteriormente, enviado para o Ceará a fim de realizar explorações filosóficas. O médico brasileiro José Pinto de Azevedo também é digno de nota. Em Angola, Azevedo ocupou-se do estudo das principais moléstias africanas como o tétano, além de ter contribuído para aprimorar o conhecimento das moléstias endêmicas do Rio de Janeiro. ${ }^{60}$

\section{Considerações Finais}

Apesar da intensa repressão da Coroa às academias ilustradas no período colonial, o raiar do século XIX já delineava uma mudança de posição política governamental em relação a tais espaços. Mesmo fortemente alicerçada aos interesses do Estado português, a Real Academia Militar do Rio de Janeiro já aparecia como um centro de dinamização do saber científico em várias frentes do conhecimento: da teoria metafísica da ciência ao pragmatismo de novas construções civis e militares por todo o território brasileiro, o novo locus era agora

\footnotetext{
58 STOIANI, R. Napoleão visto pela luneta d'El Rei: construção e usos políticos do imaginário francês e napoleônico na América Portuguesa. Tese (Doutorado em História). USP, São Paulo, 2009, p. 114.

59 MOREL, M. Pátrias Polissêmicas: República das Letras e Imprensa na Crise do Império Português na América. In: LORELAI (Org.). Iluminismo e Império no Brasil. O Patriota (1813-1814). Rio de Janeiro: Editora FIOCRUZ, 2007. p. 30.

60 DIAS, Maria Odila da Silva. Aspectos da Ilustração no Brasil. In: Revista do Instituto Histórico Geográfico e Brasileiro. Rio de Janeiro: v. 278, 1968, p. 132.
} 
exaltado pelos detentores do poder. Ademais, seguia a tendência internacional da época, com destaque para a Europa e os Estados Unidos, em que se priorizava a profissionalização e burocratização da carreira militar, mormente depois das guerras napoleônicas. Após 1815 "a maioria dos países ocidentais criou academias militares, abolindo ou relaxando as restrições quanto ao ingresso no corpo de oficiais". ${ }^{61}$ Tradicionalmente os postos militares na Europa foram circunscritos à nobreza.

A morte do conde de Linhares não só mudou a maneira de gerir a política de alto escalão no governo joanino, como também parece ter contribuído para a desvalorização da Academia Militar pelos seus substitutos. Essa importante perda política causou grandes prejuízos para a continuação do "bom desenvolvimento" da instituição. A morte de Sousa Coutinho reiterava sua ingerência em projetos culturais de seu exclusivo interesse, sendo sua ausência a principal causadora do início do descrédito do novo locus de saber. Em outras palavras, a Academia Militar tornava-se uma instância cultural que teria pouco empenho político por parte dos ministros que ocuparam seu cargo a posteriori.

No plano internacional, a morte de Linhares impulsionou a saída do conde de Funchal, que foi substituído por Palmela, da embaixada de Londres, que foi substituído por Palmela. Ademais, entre os anos de 1812 e 1815, as mudanças no cenário europeu foram de grande relevância. Com o fim das guerras napoleônicas (1814), a Paz Geral e o Congresso de Viena (1815), o Velho Mundo passava por um processo de restauração das monarquias absolutistas o que, na prática, significava uma rearticulação das alianças entre as coroas. Em 1814, D. João saudava Luís XVIII e abria os portos brasileiros ao comércio francês. Esse rearranjo político também norteou a escolha do seu novo ministério na Corte do Rio de Janeiro. Se Galveias foi o nome escolhido pelo regente para substituir interinamente o conde de Linhares, a partir de 1814 o principal ministro de D. João seria o conde da Barca que, ao sair de um longo exílio político, enfim, pôde expressar publicamente sua francofilia entre os anos de seu ministério (1814 a 1817), como no caso da chegada da comitiva dos artistas franceses em 1816.

Já Araújo de Azevedo era assaz diferente de Sousa Coutinho. Como o seu antecessor, também era um erudito com ampla experiência internacional, porém sua política em relação à cultura era mais voltada para o âmbito das artes, das belas letras e da história natural. Mesmo sendo um experiente diplomata, o avanço do conhecimento intrínseco à arte da guerra parece ter ficado em segundo plano, até porque desde 1815 a Europa vivia um período de paz. O avanço da História Natural também parecia ser o interesse prioritário de Azevedo no que concerne nomeadamente à administração da Academia Militar.

Em um âmbito mais amplo, o ministro foi um grande incentivador da vinda de naturalistas europeus para o Brasil. Até Alexander Von Humbold recomendou três naturalistas à sua proteção, fazendo-o em consideração ao elevado prestígio do ministro português nos

${ }^{61}$ DUARTE. Op. cit., p.242. 
meios científicos franceses e alemães. Conforme considera o pesquisador Antonio Pedro de Sousa Leite:

Este movimento cientifico em torno de tão importante parcela do território nacional, encontrou em Araújo o mais decidido apoio, que se traduziu sobretudo no solícito acolhimento dispensado pelo nosso compatriota a todos os homens de ciência que ao Brasil se deslocaram naquela época. ${ }^{62}$

Na documentação pesquisada, notamos que a correspondência entre a Junta Militar e os diferentes ministros dos Negócios Estrangeiros e da Guerra joaninos, além de uma prática habitual, compunha uma importante atribuição desses homens de Estado. Porém, a correspondência disponível ou preservada nos revela um dado muito curioso: durante o ano de 1817, período em que Azevedo esteve na direção de tal ministério, não encontramos nenhuma carta dirigida diretamente ao ministro. Tal fato nos coloca diante da hipótese do pouco interesse do conde da Barca para com essa instituição régia ou, quiçá, de um conflito político entre os componentes da Junta Militar e Araújo Azevedo. Consideramos também a hipótese da perda de documentação, ou ainda, a carência de estudos historiográficos sobre esse viés. De qualquer forma, é imprescindível lembrar que o projeto da academia em questão era de autoria de D. Rodrigo de Sousa Coutinho, o principal desafeto político de Azevedo. Por esse prisma, é bem plausível que os aliados do ministro anglófilo mantivessem as disputas e dificuldades no trato com o conde da Barca. Tal é o fato que, em agosto de 1816, a Junta Militar escrevia diretamente a D. João, rogando-Ihe que ponderasse sobre a frágil situação da academia, principalmente no que se referia à falta de docentes. ${ }^{63}$

A correspondência de Junta Militar com os ministros reais e com D. João é uma documentação riquíssima. A partir dela é possível que conheçamos não apenas a estrutura interna da academia, mas também os desafios cotidianos para mantê-la em funcionamento de acordo com as diretrizes do decreto régio de 1810, assim como a disputa de poder que envolvia muitos sujeitos históricos: os ministros reais, os dirigentes do locus (Junta Militar), os docentes e, por fim, os alunos. Diante dessa complexa teia de relações sociopolíticas é que se insere a difícil manutenção do locus, sobretudo depois de 1812.

Com a Real Academia Militar do Rio de Janeiro, a Coroa portuguesa objetivava metas muito ousadas. Para além da educação moral dos súditos, calcada no respeito à hierarquia militar, primava-se pela formação intelectual institucionalizada desses sujeitos. Ao valorizar o estudo em diversos níveis - das primeiras letras à produção e apreensão de um conhecimento científico de ponta -, a Coroa buscava garantir a segurança territorial do Império português em tempos de paz ou em tempos de guerra. Assim, com a alta profissionalização do exército

\footnotetext{
62 LEITE, Antonio Pedro de Souza. O Conde da Barca e o seu papel em alguns aspectos das relações culturais de Portugal com a Inglaterra e a Alemanha. Braga: Edição do autor, 1962. p. 42.

63 Ofício da Junta Militar composta por Garção Stockler, João Manoel da Silva e Manoel Jacinto de Nogueira da Gama para o Príncipe Regente D. João, em 28 de Agosto de 1816. ANRJ. IG3-2. (sem numeração de páginas).
} 
real, o governo joanino também almejava a formação de um amplo contingente de mão de obra civil especializada: os engenheiros, que cuidariam das obras de infraestrutura.

Enfim, se a Real Academia Militar do Rio de Janeiro visava, no plano ideal, provar a grandeza e solidez do Império; no plano real, enfrentou grandes obstáculos e dificuldades, pois, para além dos problemas infraestruturais - com a carência de material pedagógico e corpo docente e discente -, o locus de cultura era um projeto exclusivo de D. Rodrigo de Sousa Coutinho. Com a sua morte, portanto, a objetivação de seus ideais ficou em segundo plano para os ministros que o sucederam. A despeito disso, a exaltação do discurso de valorização do progresso através do conhecimento científico foi uma tônica imprescindível que extrapolou os muros da instituição e constituiu uma característica típica da figura do militar no período joanino, com destaque para nomes como Manoel Ferreira de Araújo Guimarães (17771838) e José Saturnino da Costa Pereira (1773-1852). Ao atuarem em muitas frentes da vida cultural, política e administrativa, diretores, lentes e alunos comporiam a administração estatal do Brasil ao longo da primeira metade do século XIX.

Juliana Gesuelli Meirelles: É autora dos livros A família real no Brasil: política e cotidiano (1808-1821). Santo André: Universidade Federal do ABC (2013) e Imprensa e poder na corte joanina: a gazeta do Rio de Janeiro. Rio de Janeiro: Arquivo Nacional (2008). Possui artigos publicados em periódicos brasileiros, elaborados individualmente ou em parcerias com historiadores nacionais, destacando-se nos últimos anos, as produções sobre história da cultura impressa e manuscrita no Império português, bem como sobre a formação e estrutura dos locus de saber (bibliotecas, academias, teatros, imprensa) e sua relação com a manutenção do poder imperial português entre fins do século XVIII e início do século XIX. 